\title{
The Great Condom Adventure: Analyzing College Students’ Narratives of Buying Condoms
}

\author{
Leslie H. Picca, Ph.D. (corresponding author) \\ Department of Sociology, Anthropology \& Social Work, University of Dayton \\ 300 College Park, Dayton, OH 45469-1442, USA \\ Tel: 937-229-3139 Fax: 937-229-3900 \\ E-mail: Leslie.Picca@notes.udayton.edu
}

Kristin E. Joos, Ph.D.

Department of Sociology and Criminology \& Law, University of Florida

P.O. Box 117330, Gainesville, FL 32611-7330, USA

Tel: 352-392-0265 Fax: 352-392-6568

E-mail: krisj@ufl.edu

\begin{abstract}
This project analyzes college students' narratives buying condoms. Research suggests young persons do not consistently use condoms, and this study will provide an in-depth analysis to students affect toward condoms. We analyzed narratives written by 115 undergraduate students of their condom buying experiences. The vast majority of the students' narratives about their condom buying experience fit a common framework, with elements including: preplanning, walking in the store, looking inconspicuous while wandering, finding the "hidden" condom location, making their selection, carrying and hiding the condoms, selecting a cashier and rushing through checkout, anticipating ridicule, and walking out of the store. Research indicates that the majority of college-aged persons are sexually active and do not always use protection. We speculate that the negative emotions associated with buying condoms, as repeated in their narratives, may contribute to young people inconsistent use of contraception.
\end{abstract}

Keywords: College students, Condoms, Sexuality, Contraception 


\section{Introduction}

Which brings us to the condom There's nothing wrong with the condom itself. The problem with condoms is still buying them. I think we should have a little secret signal with the druggist. You just walk into the drug store, you go up to the counter, he looks at you and if you nod slowly, he puts them in the bag for you. That's it.

You show up there, you put your little shaving cream, your little toothpaste on the counter.

“How are you today?” (You nod.)

“Not bad. Yourself?” (He puts them in.)

“Oh, pretty good."

And you've got them. (Jerry Seinfeld, 1993: 18)

As the passage above illustrates, purchasing condoms is often an uncomfortable activity in our society. This project analyzes college students' narratives buying condoms. Research suggests young persons do not consistently use condoms, and this study will provide an in-depth analysis to students affect toward condoms, specifically, the condom buying process. Such information may provide insight into increasing the use of condoms among young persons, hence decreasing potential unwanted pregnancy and sexually transmitted diseases (STDs).

\section{Literature Review}

Research indicates college students do not consistently use contraception when engaging in genital sexual activities (Campbell et al., 1992; Rotermann, 2005). Analyzing college students' narratives on purchasing condoms is important for it could provide insight into affective responses to condoms and thus provides clues as to why college students do not use condoms. Such information is crucial to increasing contraceptive use among college students, hence decreasing the potential increase in STDs and unwanted pregnancy. Acquiring knowledge on college students perceptions of condoms and other protections from STDs is critical since evidence suggests that people between the ages of 15 and 30 (of which college students are typically encompassed by that age bracket) are at the greatest risk of acquiring a STD, and that at least one in four people will contract a STD at some point in their lifetime (Hock, 2007).

The majority of college students have engaged in sexual intercourse (Burris et al., 2009). The average age of first intercourse is approximately 17 years old (Patrick et al., 2007). Contextually, this age is usually associated with the end of high school and inception of college. While slightly more than half of incoming first year college students have engaged in sexual intercourse, the number climbs to $86 \%$ by senior year (Siegel et al., 1999). Other researchers have pointed to the increase in risky sexual behaviors, especially oral sex, of self identified "virgins" who seek to delay vaginal-penile intercourse (Prinstein et al., 2003; Schaalma et al., 2004). Although these behaviors are not usually associated with condom use, 
STDs and HIV are transmittable via oral sex and anal sex as well as vaginal intercourse. Therefore, condom use should not only be associated with vaginal-penile penetration, but with other risky genital sex acts as well.

Unlike past generations, today's college students are coming of age in an era of "safe sex" where unprotected sex is associated with AIDS and disease. Given this, one might conclude that the convenient condom would be an ideal choice of contraception for sexually active young persons. Condoms offer many advantages that would appear to be ideal for sexually active youth. For example, unlike other contraceptive choices (oral contraceptives, Depo-Provera, Norplant, diaphragms/cervical caps, IUDs, etc.), when used properly, condoms protect against both pregnancy and STDs; condoms are not associated with any harmful side effects (except for rare allergies); condoms are a "tidy" contraception since the semen is contained in the condom; they do not require a lot of advanced planning (e.g. does not need to be taken everyday, or require a doctor's visit); and condoms are generally cheap and easily available (at a drug store, some campus health centers, etc.) (Hock, 2007). One might be tempted to conclude that given how convenient condoms are, and given that college students are aware they should practice safe sex to protect from STDs and unwanted pregnancy, college students would always use condoms. That conclusion would be wrong.

Existing research suggests that the condom is the most popular form of contraception for college students (Huber \& Ersek, 2009), however, they are not consistently used (Centers for Disease Control and Prevention, 2009). One study reports that at their most recent sexual experience, only $36.7 \%$ of sexually active college students reported using a condom (Lewis et al., 2007). Although these statistics appear to illustrate that sexually active college students use condoms at least some of the time, it is critical to remember that it only takes one sexual encounter to transmit a STD, including the HIV antibody, or for a woman to get pregnant.

Gendered experiences of men and women impact affective attitudes toward condoms. Women historically have been expected to take responsibility for the prevention of pregnancy and STDs (Edwards, 2002). However, women have the added burden of a sexual double standard in appearing "too eager" by producing a condom, and often recant the issue of using condoms (Frankel \& Curtis, 2008). In addition to complicated gender norms, sex scripts do not include verbal communications. Men and women typically employ indirect communication and signals regarding sex issues, making it difficult for young couples to negotiate condom use (Hickman \& Muehlenhard, 1999; Seal et al., 2007).

Less condom use was associated with high perceptions of invulnerability to risk (Huber \& Ersek, 2009; Thompson et al., 1996). That is, college students feel protected from STDs due to a safe sexual environment including (1) monogamy, (2) assessing partner sexual history, and (3) the ability to tell a partner's HIV status. However, each of these three topics offers young people a false protection.

First, many young people are not engaging in monogamy, but "serial monogamy" in which love and trust begin and end quickly, thus not providing a good basis for estimating STD risk (East et al., 2007). Those respondents who reported having been in a "monogamous" relationship in the past year averaged 2.3 sexual partners in the past year. Of those who had 
been involved in a relationship that their partner considered being monogamous, 19\% admitted they had engaged in sexual contact with at least one person other than their partner during the relationship (Critelli, 1998). Hence, college students should not assume a monogamous relationship is sexually safe.

Second, young persons should not feel protected from STDs based on assessing partner sexual history as studies consistently report that individuals misrepresent their sexual history. One study reports at least one fourth of college students lie to their partner about their sexual history in order to obtain sex (Critelli, 1998).

Finally, college students should not depend on being able to tell a partner's HIV status. Many diseases do not produce obvious symptoms, and in some cases, particularly among women, there may be no outward signs at all (Hock, 2007). Other symptoms of sexual diseases can take months or years to develop, even though a person is capable of infecting others regardless of visible signs. Under these circumstances, people may unknowingly infect others. Not all sexually active students are aware of their HIV status; Rouner and Lindsey (2006) found that young people report feeling confident in their knowledge of HIV and STDs, but few demonstrated this knowledge in relation to the symptoms.

As such, having detailed the necessity for condom use among young persons to protect from unwanted pregnancy and STDs, and having discussed potential reasons why college students do not use protection, this paper contributes to the literature a more in-depth analysis to students affect toward condom usage, by closely examining students' experiences purchasing condoms. Brackett (2004) conducted a similar study with undergraduate college students who were required to purchase condoms, and she offers a quantitative approach, focusing on the theme of embarrassment. As we highlight in the introductory account by comedian Jerry Seinfeld, individuals will often strategize to minimize the risk of embarrassment (such as using a secret signal, or hiding the taboo product), so as not to disrupt the social expectations (Goffman, 1967).

It is our goal to expand the knowledge on young people's condom use by adding college students' narrative responses to purchasing condoms. While scholars write prolifically about our "sexualized culture," many still suggest that conversations about sexual actions as responsible, safe, and meaningful, are rare (Attwood, 2006). Emphasizing the qualitative narratives written by the students themselves provides rich data that can help us to better examine why young people may not be using condoms. We argue that it is significant for scholarship to reflect the voices of young people's concerns about buying condoms, as it contributes one more piece to the larger dialogue about responsible sexuality choices. If we can conclude that young people's anxiety obtaining condoms contributes to their lack of using them (after all, how can young people use something they won't get), then research warrants a closer examination of their narratives.

\section{Methodology}

In this study we analyzed undergraduate students' narratives of their condom buying experiences. The narratives were written by 115 students at a large college town in the 
Southeast as an optional assignment in introductory social science courses (Principles of Sociology, Families \& Marriages, and Interdisciplinary Perspectives of Women). We contacted the students and requested their permission to access their reaction papers in order to gain insight into the lives of contemporary college students as they recounted and reacted to purchasing condoms. We assert that students' personal accounts of their experiences provide rich qualitative data that probability surveys on college students' sexual activity and condom use seem to be lacking. Insight into the often complex task of obtaining condoms may reveal why so few students use them.

\subsection{Sample}

The sample consisted of 115 narratives written as an optional assignment by undergraduate students enrolled in undergraduate social science courses taught by one of the authors. Almost two-thirds of the students enrolled in the classes chose to participate in the optional assignment during the course unit on sexuality; only a few students opted for an alternative assignment to buying condoms for extra credit. Of the 115 reaction papers that were included in the analysis, $77 \%$ were written by women, $23 \%$ by men. For the racial composition, $62 \%$ of the students identified themselves as "white," $21 \%$ identified as "black," $12 \%$ identified as "Hispanic or Latino," and 5\% identified as "Asian” or "Indian." About half of the students were in their first or second year at the university, and less than a quarter were sociology majors.

\subsection{Procedure}

The students enrolled in the courses were given three extra credit options as part of the sexuality unit: they could choose to write a brief reaction paper about their experiences purchasing a box of condoms, getting tested for HIV, or visiting Planned Parenthood. The majority of those who participated decided to purchase a box of condoms and write about their experience. Consistent with the Institutional Review Board (IRB) protocol, students were able to complete the assignment for extra credit, and then decide later if they wanted to voluntarily submit the write-up of their condom buying experience to the researchers. All of the students who submitted reaction papers about their condom buying experience signed informed consent forms indicating their permission for the researchers to analyze their accounts. The students were assured that their identity would remain confidential and all identifying characteristics were changed. We systematically analyzed each of the accounts using grounded theory (Glaser \& Strauss, 1967), where the data are examined inductively, and the analysis is not set up to confirm or disconfirm specific hypotheses. Rather than imposing set categories on the data, categories and themes emerged from the data. As discussed in the results, relying on a ground theory approach illustrates how the elements of the "condom buying process" emerged from the student narratives and largely all fit a common framework (discussed below).

\subsection{Limitations}

Given the relatively small sample size, the accounts of the students analyzed in this study may not be representative of all college students. As we do not know what caused some 
students to participate in this assignment compared to an alternative assignment, caution must be exercised in generalizing the results to all college students. However, this study provides insight into the condom buying experience, frequently characterized as stressful and difficult, for some college students and may lend understanding as to why so many students engage in unprotected sex.

\section{Results}

Even though this was an optional assignment and students were able to select alternative projects or choose not to participate, more than half of the students opted to purchase a box of condoms and submit a brief reaction paper about their experience doing so. Often students specified that the reason they chose this assignment in lieu of the others was because they thought it would be easy in comparison. One woman wrote, "When I chose this assignment, I figured it would be a 'breeze.' However, as I entered (the store) I found myself becoming nervous." Many students reiterated that they thought it would be "no big deal."

The vast majority of the students' narratives about their condom buying experience fit a common framework. The elements of the framework consisted of a series of steps from strategizing the trip to the store, to the encounter with the cashier and exiting out the door. The titles of the students' narratives often foreshadowed the emotional intensity that they experienced. Titles included telling examples such as, "The Ordeal," "Shocker: The First Time I Bought Condoms," "The Great Condom Adventure," "Me Buying Condoms?!?" Students then proceeded to tell a common narrative with elements including: preplanning, walking in the store, looking inconspicuous while wandering, finding the "hidden" condom location, making their selection, carrying and hiding the condoms, selecting a cashier and rushing through checkout, anticipating ridicule, exiting the store, and reflecting on their experience.

\subsection{Preplanning}

Before the actual trip to the store many students spent time and energy procrastinating and planning their purchase. Students took care to plan which store to shop at, and the time of day at which to make their (often dreaded) adventure. For example, according to Maria, " $I$ decided if I was going to purchase condoms that I would need to do it in the most empty store I could think of. This would be (the store) around 12 at night...Perhaps you are wondering why I went so late at night? I did this because I wanted the least amount of people to see me buying condoms."

Students also contemplated whether or not to go alone or bring a friend. Most students indicated a preference for making this journey alone while others sought the accompaniment of a friend for reassurance. However, with rare exception, students indicated that they did not want to purchase the condoms with the partner with whom they planned to use them. One woman indicated, "My boyfriend waited in the car because we were both feeling too shy to go in together. We were worried about what the little old lady at the cash register would think of us if she saw us both together purchasing a package of condoms." Despite such efforts in planning, students still struggled with the task at hand, purchasing a box of condoms. 


\subsection{Walking in the Store \& Wandering the Aisles}

Once students made the decision to initiate the purchasing experience and actually venture to their chosen store, they did not eagerly proceed. Students reported procrastinating and feeling the need to build up the courage to even walk through the doors of the store. Robin describes, "I thought I wouldn't be phased, but as I drove up to the store, I didn't want to get out of my car. I sat there and asked myself what the problem was...I started to feel silly sitting in the parking lot so I got out and went in." Another student, Rachel, was not only nervous, she reports the physical manifestation that anticipating the condom buying experience had on her. She explains, "As I got out of my car to walk over to the entrance of Walgreen's, my legs felt stiff. I was so nervous, I knew this was going to be one of the most embarrassing moments of my life." This psychosomatic reaction would seem ludicrous if we substituted buying a pack of condoms for buying a pack of gum. Yet, such severe responses occurred throughout the entire framework of the condom buying experience. One student, Jim, actually went so far as to cast the situation as a strategic battle-game, literally mission impossible:

I wondered to myself how I would ever build up the required amount of courage to simply walk over to the counter and pick up a box of Trojan brand condoms, I literally made a game out of it, like Mission Impossible. My objective was to secure a box of condoms with as little awkwardness as possible, without drawing much attention to myself.

Much like Jim's secret mission, other students also went to great efforts to look inconspicuous. Casey says, "I walked around the store for a while trying to look as though I wasn't shopping for anything important... I felt like I was wearing a sign 'I'm here to buy condoms.' It seemed like all eyes were on me, judging me." As Casey illustrates, attention was given to how others perceived and judged them, particularly older adults and parents. Another woman indicated, "I felt very paranoid like someone I knew might be watching me from around the corner, or that the surveillance cameras were just focused on me, and that my parents would be shown what was recorded on those cameras."

\subsection{Finding the Hidden Condom Location and Making their Selection}

The students made their condom purchases in various drug stores, discount chains, and supermarkets each with their own store layout, thus making the condom aisle difficult to locate. Maria remarked, "Where in the store do I actually find the condoms??? Well obviously I wasn't about to ask anybody to point me in the direction of the condom section. So I searched the store myself." As exemplified by Maria, many students had trouble finding the condoms, but most did not dare ask an associate. However 8\% of the students felt comfortable enough to seek assistance from an employee. Mohammed recounts, "I went to one store and after walking around for 20 minutes without a clue to where they were, I had to ask the cashier for them." From these students' accounts, the condoms seem to be hidden, thus emphasizing the taboo connotation of the product.

Once the condom aisle was located, students were faced with deciding which of the multitude of varieties to choose. Factors included price, brand, style, color, size, pleasure enhancing features, and additives like lubrication and spermicide. According to Sydney, "I thought a 
condom was a condom. I never realized what a big decision it was. There were so many choices. Did I want latex or not? Ribbed or smooth? Flavored or not? Lubricated or not? What color? What size? How many? Which brand?" Men were more likely to be familiar with their preferred condom type. Jacob declares, "I always buy the Durex brand so I can grab them and just get away from the section. Also I know Durex is the world's bestselling brand of condoms."

\subsection{Carrying and Hiding the Condoms}

Now that I actually had the condoms in my hand, things just got worse. I didn't want to carry them around the store. I just wanted to stick them in my pocket until I got to the cash register but it would look like I was trying to steal them. So that option was out of the question. So I snuck around to the snack section and took a box of crackers off the shelf to hide the condoms behind as I made the short walk to the register. Though the walk was short, it seemed like it took forever.

This quote from Maria illustrates the extreme discomfort many students experienced, to the extent that they both wanted desperately to hide the product and rush to the register. If we were to substitute the box of condoms with a box of tissues, this reaction seems absurd. Attempts were made to "camouflage the product" with other more neutral items. Heather claimed, "Condoms were the only items on my list to get that day, but I could never go to the register with just a box of condoms. So I also picked up magazines, gum, and candy to cover up the very obvious packaging of the box." Once the item was secured in hand, many students reported darting to the checkout.

\subsection{Selecting a Cashier and Rushing through Check-Out}

The vast majority students indicated a preference for a cashier who was female, young, and "non-maternal." One student even reported waiting five minutes for a female cashier to start working the checkout counter. Some students hinted that a woman employee might be less likely to ridicule them or make embarrassing comments. Samantha noted, "I scanned down several checkout lanes to find the person that I would feel the most comfortable making my purchase with. I decided on a girl who was about 20..."

Similar to the psychosomatic symptoms that were mentioned earlier by Rachel as she walked in the store, Hannah revealed an intense bodily sensation:

The next thing I knew I was waiting in line and I was the next person up to be scanned. I got this sensation throughout my body as if I was just about to take a test. You know, the feeling that overcomes you when you get all nervous inside and don't know what to expect...I told myself to take a deep breath and it'd all be ok.

Recall that this is simply a college-aged woman buying a box of condoms and yet this condom buying signifies something much more profound than buying a less sexually loaded item like candy or gum.

\subsection{Anticipating Reactions}




\section{MlMacrothink}

Journal of Sociological Research

ISSN 1948-5468

2009, Vol. 1, No. 1: E4

Given that students are purchasing an item that is often the subject of an urban legend (the dreaded condom price-check over the store's loudspeaker), just before checking out, some students conjured up elaborate excuses in case they were questioned. As an example of this, Zack remarked, "Would I tell them that I'm buying them for me? No, I couldn't do that. I would have to think of a lie very quickly, something like, oh these aren't for me, these are for my buddy in the car or something like that."

Others were prepared to explain that this was a class assignment, thus justifying their purchase. Rachel wrote, "To my surprise, the cashier was a young man. He said, 'I know what you're going to be doing tonight.' I was so embarrassed...I explained to him that I was doing this for one of my classes. I could tell he didn't believe me." As this example shows, although most students did not encounter queries or disparaging remarks and did not have to account for their purchase, a small minority of students dealt with embarrassing situations.

\subsection{Exiting the Store \& Reflections}

Common reactions expressed by students when walking out of the store include feeling: relieved, embarrassed or that they were "never doing that again," that it was really no big deal, a sense of pride, or feeling that they could never shop at that store again.

Although this was an optional assignment, many students felt grateful for being encouraged to purchase a package of condoms as this was commented as the "first time" for $73 \%$ of the women and $26 \%$ of the men. Samantha exclaimed, "And now I feel so much more comfortable with the situation. I really think that the assignment helped me and now if I ever do need to buy condoms in the future the situation will not be as intimidating."

Some women stated that they felt this was a rewarding experience like the following statement from Rebecca, "I actually felt proud as she handed me the change. I felt like a responsible (young) adult for buying protection against STDs \& unwanted pregnancy." However, not all women shared in this sense of accomplishment; 8\% of the women indicated that they would "never do that again." According to Emma, "Needless to say that this is the absolute last time I ever buy condoms again. I'll just leave that job for [boyfriend] to do in the future."

As well as the framework that was detailed above, a few students also wrote about experiences that were tangential to the common framework and are worth mentioning. For example, many of the male respondents associated condom buying with ensuring sexual pleasure, an association none of the female students linked. Jesse wrote, "I quickly picked Trojan (sensitive) because I thought they would be fun!" Just a few of the males noted that the association of condoms with sexual pleasure was suggested to them by a sales associate, as Andrew commented, "“[The associate] took me straight to the lubricated, ribbed Trojans. She told me these ones were sure to make a girl be heard all the way in [nearby town]. How could I refuse." Interestingly, one male, Steve, appeared to be disturbed at the suggestion that condoms enhanced sexual pleasure:

"The package said, "ribbed for her pleasure." Why the hell are they ribbed for her pleasure? I'm going to be the one wearing them! What exactly does that mean anyway? If the condom is 
giving her the pleasure and not me, then I must be doing something very wrong--very wrong."

Steve insinuates that the condom should pleasure him, and not his female partner. Steve is assuring the reader that his partner's sexual pleasure was not dependent upon the condom features, but on his sexual skills.

Another key category that emerged as students recounted their condom buying experiences included the intent of the condom. In other words, some students reported that their anxiety with buying condoms was directly related to the general assumption that it is equated with participating in some type of sexual activity (typically vaginal-penile penetration). According to Kerri, "In the grocery store, [with other products] you can play it off: you go in and buy spaghetti sauce and you could be making lasagna or spaghetti or even using it as pizza sauce. But when you buy condoms, there's just no escape because they're not a multi-functional item." Not only are condoms not typically thought of as "multi-functional," but condoms are associated with a specific function that is loaded with significant and emotional meanings.

Perhaps in part due to the specific nature of condoms, many students seemed to feel compelled to inform their audience about their own sexual experiences. Jim clearly stated, " $I$ am in no way promiscuous nor do I lead a promiscuous lifestyle, I feel I just had to make that clear on my behalf." Other students echoed Jim's declaration, ensuring their instructor that they had "not engaged in sex" and were only buying the condoms for the extra credit class assignment. Samantha said, "Buying condoms is something that I have never considered doing before. It is not something that I have ever had to worry about because I have never placed myself in any situation where I would have to deal immediately with the issue of sex. I am innocent and naïve and I pretty much like it that way." Although Samantha doesn't claim that she has not engaged in sexual activity, she does seem to be linking buying condoms with sex and the loss of innocence.

\section{Discussion}

Having described the common framework of students buying condoms and the three experiences that are tangential (sexual pleasure, intention of the condom, and revealing sexual in/experiences), many themes emerged as students' told their stories of the condom buying experience. Two prevalent themes that consistently emerged include comparing it to other "taboo" products, and commenting on who is judged to be "acceptable" to buy condoms (related to public and private spaces).

The first theme to emerge in analyzing the students' condom writing experiences is comparing condoms to other "taboo" products. Typically items such as tampons and diarrhea medicine were mentioned, as Julia illustrates, "When it came time for me to prove that I was adult enough to buy condoms I really had a hard time with it. I suppose it is comparable to buying tampons. It took me a few years of having my period before I could buy feminine products without agonizing over it." This narrative foreshadows the second prevalent theme, who is judged to be "acceptable" to buy condoms.

In the second theme, students expressed that they considered gender and age to be important 
factors when reflecting on who "should" buy condoms. That is, students expressed that while it is "okay" for men to buy condoms, women who did so were perceived to be sexual promiscuous. Makayla comments, "I felt like they [condoms] were screaming 'I'm a hoe!' This is not true, but...I can't remember when I didn't think that a woman having sex often was a hoe." In addition to gender, age also played a role in affecting considerations of who is deemed to be acceptable to buy condoms. Luis stated, "She [cashier] probably did not think it odd for a young male to buy condoms. Now if I were extremely young or very old it probably would have elicited a reaction from her." As these two quotes illustrate, students' statements reflect ideas about who is permissible to be openly sexual, mimicking society's standards of who can or cannot be sexual. Not only does the sexual "double standard" exist with gender, that is, it is acceptable and encouraged for men to be unashamedly blatant about their sexual prowess compared to women. According to many students, the sexual double standards exist for age, where it is permissible only if the consumer is not too old or too young.

Numerous students commented that the gender and age of the condom buyer is critical to factor in when accounting for the condom buying experience. Jacob attributed his mundane shopping experience to his gender, "Overall, the experience was quick and inconsequential because of my longtime purchase of the product and the fact that I'm a male." Elijah echoed Jacob's claim that condom buying is affected by gender, "I also think it would be different for a girl to buy condoms than a boy. I've personally never seen a girl buy them.” Not only did male participants remark about the gender differentials, as Destiny wrote, "I think I have this idea that it is not socially acceptable for a woman to go in the store and buy condoms." Brianna also remarked that women should not be the condom purchasers, "In my mind that was the guys job and their responsibility." There are a few reasons this may be the case; condoms are designed to be worn by the male genitalia, and so perhaps some students feel that males should be the gender responsible for acquiring the condoms. We can speculate that this conception is also drawing upon the sexual double standard whereby women are chastised for being sexually active whereas men are praised. This is evident in Destiny's phrase that condom buying is "not socially acceptable for a woman."

Gender and age are not only critical to consider in the person purchasing the condoms, but was also mentioned in who the students perceived to judge them. Many students suspected everyone in the store to judge them (often negatively), however older people and maternal figures were of particular concern. Isaiah wrote, "I was also afraid about what an elder person or mother would be thinking of me if they saw me buy a pack of condoms." Antonio commented that he was concerned not only with maternal figures, but with children's reactions as well, "I got to the register and the lady in front of me had a child. A little girl none the less. I may have been over dramatizing the situation, but I felt like a pervert."

Not all men "felt like a pervert" buying condoms. More men tended to associate buying condoms with a positive connotation, such as sexual achievement and responsibility. Larry said, "I began to think of it this way: if people are watching you or judging you it is probably because they're not having sex, but if they are, then they understand." Mark also remarked about what he thought people were thinking of him buying condoms, "When I think back 
about the people in the store, like the cashier and the people waiting behind me, probably thought I was an intelligent and common sense oriented guy." Unlike the men, more women tended to perceive others were thinking of them in more neutral or negative judgments. Jade remarked, "They might think I am a girl that knows what she wants or they could just think that I am sleeping around."

Ashley also commented about the negative perceptions she had of strangers reaction to her buying condoms, "I do not know why I was on edge during this situation, but the best I can figure was, that if people saw me buying condoms then they would think less of me, and more important they would be in my private world by knowing I was sexually active." Her statement goes deeper than a negative perception, as she also reflects on how her private space of sexual activity crashes into the public space of the store. Mark notes, "It felt weird due to what seemed to be a non private matter in the store. I mean other customers in the store, strangers, see you pick up the package and right away they know what your intended idea is for the purchase. In buying the condoms in a store it allows the public in your business since they know what you will do with the condoms." Condom buying is significant if we recall that condoms are associated with sexual activity, which carries significant meanings. Sexual activity, particularly sexual intercourse is not just a "neutral activity” such as shaking somebody's hands. Sexual activity typically is loaded with emotional significance (from recreational fun to an indication of relationship bonding).

From the aforementioned student narratives, it quickly becomes apparent that the majority of the students reported feeling uncomfortable (to say the least) purchasing condoms. When some of the students' contexualized their experiences in the location where the purchasing took place, many noted that their tentative (and often quite negative) affective responses may have been unsubstantiated. Erika commented, “Hey, I'm in [college town] now, home of 45,000 sexually active collegians. How bad can it be?" suggesting that purchasing condoms should not be so challenging given their location. Ashley reiterated this by stating, "I found the situation funny because I realize I was making a bigger deal out of the situation then it actually was. I mean hello, I am in college, and not even that but I live in a college town. So I would hope and assume that women and men are in here quite often making the same purchase."

Obviously from the accounts, many of the college students felt uncomfortable purchasing condoms. This begs the question, where are the students getting their protection from, if they use any at all. A few students answered this question in their narratives. Luis responded that he gets his condoms for free at a health care center, hence he doesn't have to deal with any of the uncomfortable feelings some associate with buying condoms, "Even then I don't have to buy any [condoms] since my wife gets the condoms for free at the women's clinic." Less reported were students who got their condoms from authority figures, as Jesse comments, "From the beginning my mom would provide me with condoms 'just-in-case'." One student reported that he got his condoms from an unlikely source, as Andrew states, "I have gotten most of my condoms from the gentleman that rides around [the city] on his bike with a dufflebag of Lifestyles. This guy hands out condoms for free, with a donation to his (alcohol) cause, of course." Interestingly, unlike a few of the men, none of the women commented in 
their accounts how they acquired condoms (in situations outside of this assignment), perhaps suggesting that it is often considered to be the responsibility of men.

\section{Conclusion}

As stated in the literature, the majority of students do not consistently always use condoms. As evident from this research, one explanation for this finding is that college students do not feel comfortable buying condoms. Consistent with Cooley's looking glass self (Cooley, 1902), the students expressed concern over what they thought other people were thinking of them. Purchasing condoms for many people was an intrusion of their private sexual worlds into the public consumer world. Like many students, Dawn stated, "I don't have to be enthusiastic about announcing to the whole world that I'm going to have sexual intercourse."

Limitations of the study are notable, such as for example, we do not know for sure the age and life experiences of all the students. Although we know the approximate age cohort (traditional-age college students), we could hypothesize that younger students, for example an 18 year old first year student compared to a 23 year old senior, would experience different levels of comfort with the condom buying process. Additionally, this study was not designed as a causation analysis, and therefore we cannot make any speculation about what specifically caused some students to feel more or less comfortable purchasing condoms. Finally, discussions of condom use often make heterosexist assumptions, that is, it is assumed that the condoms are used for heterosexual vaginal-penile penetration only. Though we attempt to avoid this bias, we realize that this paper does not address other ways condoms may be employed by heterosexual, lesbian, gay, bisexual, transgender, and queer people.

Not only did we find this study to be provocative and entertaining, we believe the results have some notable implications and beneficial applications. These qualitative narratives are critical to consider when policy makers contemplate how to encourage young people to protect themselves from STDs and unplanned pregnancies. Ideally, every person would feel comfortable taking control of their sexuality, of protecting themselves-and often that includes buying condoms. As previously mentioned, research indicates that the majority of college-aged persons are sexually active and engage in risky sexual behavior at least some of the time. We speculate that the negative emotions associated with buying condoms, as repeated in their narratives, may contribute to young people not consistently using protection. This leads us to questions which future research might consider: how do we destigmatize the condom (or at least purchasing the condom)? Can we, as researchers, make the assumption that just because people feel uncomfortable purchasing condoms that they also resist using them? Future research may expand this study to look at affective responses to obtaining and using other forms of contraceptives.

\section{Acknowledgement}

The authors wish to thank Dr. Connie Shehan, and the two anonymous reviewers for their generous and constructive feedback. 


\section{References}

Attwood, F. (2006). Sexed up: Theorizing the sexualization of culture. Sexualities, 9 (1), 77-94.

Brackett, K. P. (2004). College students' condom purchase strategies. The Social Science Journal, 41,459-464.

Burris, J. L., Smith, G. T., \& Carlson, C. R. (2009). Relations among religiousness, spirituality, and sexual practices. Journal of Sex Research, 46 (4), 282-289.

Campbell, S. M., Peplau, L. A., \& DeBro, S. C. (1992). Women, men, and condoms: Attitudes and experiences of heterosexual college students. Psychology of Women Quarterly, 16, 273-288.

Caron, S. L., Davis, C. M., Halteman, W. A., \& Stickle, M. (1993). Predictors of condom-related behaviors among first year college students. The Journal of Sex Research, 30 (3), 252-260.

Cecil, H. (1998). Meanings assigned by undergraduates to frequency statements of condoms use. Archives of Sexual Behavior, 27 (5), 493-506.

Centers for Disease Control and Prevention. (2009). Sexual and reproductive health of persons aged 10-24 years-United States, 2002-2007, Surveillance summaries. Morbidity and Mortality Weekly Report, 58 (6), 6-9.

Cooley, C. H. (1902). Human nature and the social order. New York: Charles Scribner's Sons.

Critelli, J. W. (1998). Obstacles to condom use: the combination of other forms of birth control and short term monogamy. Journal of American College Health, 46 (5), 215-220.

Darling, C. A., Davidson, Sr., J. K., \& Passarello, L. C. (1992). The mystique of first intercourse among college youth: The role of partners, contraceptive practices, and psychological reactions. Journal of Youth and Adolescence, 21 (1), 97-117.

DeBro, S. C., Campbell, S. M., \& Peplau, L. A. (1994). Influencing a partner to use a condom: a college student perspective. Psychology of Women Quarterly, 18 (2), 165-183.

Desiderato, L. L. \& Crawford, H. J. (1995). Risky sexual behavior in college students: relationships between number of sexual partners, disclosure of previous risky behavior, and alcohol use. Journal of Youth and Adolescence, 24 (1), 55-69.

East, L., Jackson D., O’Brien L. \& Peters K. (2007). Use of the male condom by heterosexual adolescents and young people: literature review. Journal of Advanced Nursing, 59 (2), 103-110.

Edelgard, W. \& Wan, C. K. (1993). Condom use: A self-efficacy model. Health Psychology, 12 (5), 346-353.

Edwards, M. (2002). Contraceptive choice: responsibility of both women and men. SIECUS 
Report, 31 (2), 2.

Frankel, A. \& Curtis, D. A. (2008). What's in a purse? Maybe a woman's reputation. Sex Roles, 59, 615-622.

Glaser, B. \& Strauss, A. (1967). The discovery of grounded theory. Chicago: Aldine.

Goffman, E. (1967). Interaction ritual. Chicago: Aldine.

Hickman, S. \& Muehlenhard, C. (1999). "By the semi mystical appearance of a condom”: How young women and men communicate sexual consent in heterosexual situations. Journal of Sex Research, 36 (3), 258-272.

Hock, R. R. (2007). Human sexuality. Upper Saddle River, NJ: Pearson Education, Inc.

Huber, L. R. B. \& Ersek, J. L. (2009). Contraceptive use among sexually active university students. Journal of Women's Health, 18 (7), 1063-1070.

Lewis, M. A., Lee, C. M., Patrick, M. E., \& Fossos, N. (2007). Gender-specific normative misperceptions of risky sexual behavior and alcohol-related risky sexual behavior. Sex Roles, 57, 81-90.

Murstein, B. I. \& Mercey, T. (1994). Sex, drugs, relationships, contraception, and fear of disease on a college campus over 17 years. Adolescence, 29 (119), 303-322.

Oswalt, R. \& Matsen, K. (1993). Sex, AIDS, and the use of condoms: a survey of compliance in college students. Psychological Reports, 72 (3), 764-767.

Patrick, M. E., Maggs, J. L., \& Abar, C. C. (2007). Reasons to have sex, personal goals, and sexual behavior during the transition to college. Journal of Sex Research, 44 (3), 240-249.

Prinstein, M., Meade, C., \& Cohen, G. (2003). Adolescent oral sex, peer popularity, and perceptions of best friends' sexual behavior. Journal of Pediatric Psychology, 28, 243-249.

Rotermann, M. (2005). Sex, condoms, and STDs among young people. Health Reports, 16 (3), 39-45.

Rouner, D., \& Lindsey, R. (2006). Female adolescent communication about sexually transmitted diseases. Health Communication, 19 (1), 29-38.

Schaalma, H., Abraham, C., Gilmore, M. R., \& Kok, G. (2004). Sex education as health promotion: What does it take? Archives of Sexual Behavior, 33, 259-269.

Seal, D. W., O’Sullivan, L. F., \& Ehrhardt, A. A. (2007). Miscommunications and misinterpretations: Men's scripts about sexual communication and unwanted sex in interactions with women. In M. Kimmel (Ed.) The sexual self: The construction of sexual scripts (pp. 141-161). Nashville: Vanderbilt University Press.

Seinfeld, J. (1993). SeinLanguage. New York: Bantam Books.

Siegel, D. M., Klein, D. I., \& Roghmann, K. J. (1999). Sexual behavior, contraception, and risk among college students. Journal of Adolescent Health, 25, 336-343. 
Thompson, S. C., Anderson, K., Freedman, D., \& Swan, J. (1996). Illusions of safety in a risky world: a study of college students' condom use. Journal of Applied Social Psychology, 26 (3), 189-211. 